\title{
Atributos de fertilidade e frações húmicas de um Latossolo Vermelho no Cerrado
}

\author{
Ademir Fontana $^{(1)}$, Marcos Gervasio Pereira( ${ }^{(1)}$, Arcângelo Loss ${ }^{(1)}$, Tony Jarbas Ferreira Cunha ${ }^{(2)}$ \\ e Júlio César Salton ${ }^{(3)}$
}

\begin{abstract}
(1)Universidade Federal Rural do Rio de Janeiro, BR 465, Km 7, CEP 23890-000 Seropédica, RJ. E-mail: ademir.fontana@gmail.com, gervasio@ufrrj.br, arcangeloloss@yahoo.com.br (2)Embrapa Semi-Árido, BR 428, Km 152, Zona Rural, Caixa Postal 23, CEP 56302-970 Petrolina, PE. E-mail: tony@cpatsa.embrapa.br (3)Embrapa Agropecuária Oeste, BR 163, Km 253, CEP $79804-970$ Dourados, MS. E-mail: salton@cpao.embrapa.br
\end{abstract}

Resumo - O objetivo deste trabalho foi avaliar os atributos de fertilidade e as frações de matéria orgânica, ácido fúlvico, ácido húmico e humina, em um Latossolo Vermelho distroférrico, sob diferentes sistemas de cultivo no Cerrado. Os experimentos foram conduzidos no período de 1993 a 2003. Os tratamentos foram divididos em quatro grupos: lavoura (1 e 7), rotação lavoura/pastagem (3 e 5), rotação pastagem/lavoura (4 e 6) e pastagem contínua (2 e 8), todos em plantio direto. A avaliação do solo foi feita após dez anos de cultivo, com análises químicas de amostras da profundidade de $0-20 \mathrm{~cm}$. Foi observado que os teores de $\mathrm{Ca}^{2+}$ variaram de 4,6 $\mathrm{cmol}_{\mathrm{c}} \mathrm{kg}^{-1}$ (lavoura) a 6,20 $\mathrm{cmol}_{\mathrm{c}} \mathrm{kg}^{-1}$ (pastagem contínua), e os de P disponível, de 1 a $6 \mathrm{mg} \mathrm{kg}^{-1}$. Os teores de $\mathrm{Mg}^{2+}$ variaram de $3 \mathrm{cmol}_{\mathrm{c}} \mathrm{kg}^{-1}$, sob lavoura/pastagem, a 3,8 $\mathrm{cmol}_{\mathrm{c}} \mathrm{kg}^{-1} \mathrm{em}$ pastagem contínua, e os de $\mathrm{K}^{+}$, de $0,28 \mathrm{cmol}_{\mathrm{c}} \mathrm{kg}^{-1}$ sob pastagem contínua, a 1,10 $\mathrm{cmol}_{\mathrm{c}} \mathrm{kg}^{-1}$ em lavoura/pastagem. Os teores de $\mathrm{C}$ orgânico variaram de $16,6 \mathrm{~g} \mathrm{~kg}^{-1}$ na lavoura a $28,0 \mathrm{~g} \mathrm{~kg}^{-1}$ sob lavoura/pastagem. A fração humina apresenta os maiores valores entre as frações da matéria orgânica.

Termos para indexação: rotação de culturas, plantio direto, propriedades químicas.

\section{Fertility properties and humic fractions in a Rhodic Ferralsol in Brazilian Cerrado}

\begin{abstract}
The objective of this study was to evaluate fertility attributes and the fractions of organic matter, fulvic acid, humic acid, and humina, in a Rhodic Ferralsol, under different cultivation systems in Brazilian Cerrado. The experiments were carried out from 1993 to 2003. The treatments were divided in four groups: tillage (1 and 7), rotation tillage/pasture ( 3 and 5), rotation pasture/tillage (4 and 6), and continuous pasture (2 and 8), all in no-tillage system. Chemical analyses of soil samples were made for the depth of $0-20 \mathrm{~cm}$, after ten years of cultivation. It was observed that $\mathrm{Ca}^{2+}$ content varied from $4.6 \mathrm{cmol}_{\mathrm{c}} \mathrm{kg}^{-1}$ (tillage) to $6.20 \mathrm{cmol}_{\mathrm{c}} \mathrm{kg}^{-1}$ (continuous pasture), and available $P$ from 1 to $6 \mathrm{mg} \mathrm{kg}^{-1}$. The $\mathrm{Mg}^{2+}$ content varied from $3 \mathrm{cmol}_{\mathrm{c}} \mathrm{kg}^{-1}$, under tillage/pasture, to $3.8 \mathrm{cmol}_{\mathrm{c}} \mathrm{kg}^{-1}$ in continuous pasture, and $\mathrm{K}^{+}$, from $0.28 \mathrm{cmol}_{\mathrm{c}} \mathrm{kg}^{-1}$, under continue pasture, to $1.10 \mathrm{cmol}_{\mathrm{c}} \mathrm{kg}^{-1}$ in tillage/pasture. It was verified that organic $\mathrm{C}$ content varied from $16.6 \mathrm{~g} \mathrm{~kg}^{-1}$ in the tillage, to $28.8 \mathrm{~g} \mathrm{~kg}^{-1}$ under tillage/pasture. The humine fraction presents the largest values among the organic matter fractions.
\end{abstract}

Index terms: crop rotation, no-tillage, chemical properties.

\section{Introdução}

Estudos no Cerrado vêm sendo conduzidos, com o objetivo de desenvolver estratégias para uma utilização sustentável dos solos, no sentido de reduzir o impacto das atividades agrícolas sobre esse ambiente, onde as altas temperaturas e o manejo de solo mais adotado (plantio convencional e uso em monocultivo) podem levar a um declínio acelerado dos estoques de carbono e nitrogênio de origem orgânica (Freixo et al., 2002; Torres et al., 2005).
Em estudos de solos do Cerrado, Souza \& Alves (2003) observaram limitações nutricionais para diferentes culturas, em decorrência da baixa fertilidade natural. No entanto, as propriedades físicas favoráveis ao cultivo possibilitam a agricultura mecanizada intensiva, uma vez corrigidas as deficiências químicas (Cerri et al., 1991).

Os sistemas plantio direto e cultivo mínimo, quando associados à rotação de culturas anuais, alteraram as propriedades químicas do solo, com aumento dos teores de matéria orgânica (Paiva et al., 1997), variações no 
pH do solo, na capacidade de troca catiônica (Souza \& Alves, 2003), bem como nas bases trocáveis e no P disponível (Selles et al., 1997), além da diminuição do alumínio tóxico, em relação ao sistema convencional (Silveira \& Stone, 2001).

O plantio direto, comparado ao plantio convencional, diminui a velocidade de degradação da matéria orgânica do solo (MOS), pelo menor revolvimento deste e maior preservação dos resíduos vegetais em sua superfície. Hermani et al. (1999) observaram, no sistema plantio direto, o aumento do estoque de carbono orgânico, nas camadas superficiais do solo, e, conseqüentemente, aumento nos teores das frações orgânicas, o que sugere uma maior estabilidade do sistema plantio direto, em comparação ao convencional.

A MOS interage com a fase mineral, interferindo, assim, na dinâmica de nutrientes no sistema solo-planta, exercendo um papel importante na manutenção da fertilidade do solo, termo cujo conceito global se estende, também, às propriedades físicas e biológicas (Mendonza et al., 2000; Silva et al., 2000).

Ao estudar o húmus de solos brasileiros, Volkoff \& Cerri (1988) concluíram que a acidez, a aeração e a temperatura, nessa ordem de importância, são os principais fatores que influenciam em sua natureza. Segundo Vaughan \& Ord (1985), a importância das frações humificadas, na dinâmica dos elementos no solo, se estende também às interações com os fertilizantes, que podem ter sua efetividade aumentada ou reduzida, além de ser amortecidos os efeitos adversos de altas doses; isto regula as condições de nutrição mineral de plantas.

A quantidade da matéria orgânica e a proporção das frações húmicas têm servido como indicadores de qualidade de solo, em razão da forte interação das substâncias húmicas com o material mineral e o manejo do solo (Fontana et al., 2001; Silva, 2005).

Este trabalho teve como objetivo avaliar os atributos de fertilidade e as frações de matéria orgânica, ácido fúlvico, ácido húmico e humina, em um Latossolo Vermelho distroférrico, sob diferentes sistemas de cultivo no Cerrado.

\section{Material e Métodos}

O trabalho foi realizado com amostras coletadas em um experimento de longa duração, instalado em 1993 na Fundação Mato Grosso do Sul, no Município de Maracaju, MS. A área experimental está localizada en- tre as coordenadas $21^{\circ} 37^{\prime} \mathrm{S}$ e $55^{\circ} 8^{\prime} \mathrm{W}$, a aproximadamente 384 m de altitude, sob clima tropical CWa na classificação de Köppen, com inverno acentuadamente seco e verão quente e chuvoso.

Foram instaladas parcelas inteiramente casualizadas, de $1.500 \mathrm{~m}^{2}$ cada, em Latossolo Vermelho distroférrico, textura muito argilosa. Em dezembro de 1992, foi

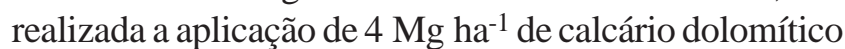
ao solo, com aração e gradagem; também foram aplicados $400 \mathrm{~kg} \mathrm{ha}^{-1}$ de superfosfato simples. Os diferentes sistemas de cultivo e a adubação utilizada em cada tratamento são apresentados na Tabela 1.

Os tratos culturais foram feitos de forma mecanizada, conforme as recomendações técnicas para as respectivas culturas, em semeadura direta. As variedades de cada cultura variaram ao longo dos anos, tendo sido empregadas as de uso mais comum na

Tabela 1. Seqüência de espécies utilizadas nos diferentes sistemas de cultivo, entre 1993 e 2002, adubação realizada em cada um dos tratamentos, e cultivos realizados em plantio direto.

\begin{tabular}{|c|c|c|}
\hline $\mathrm{T}^{(1)}$ & $\begin{array}{l}\text { Sistemas de } \\
\text { cultivo/rotação }\end{array}$ & Adubação \\
\hline 1 & Soja/aveia & $\begin{array}{l}\text { Soja com } 350 \mathrm{~kg} \mathrm{ha}^{-1} \text { de adubo } \\
\text { formulado } 0-20-20 \text { a cada semea- } \\
\text { dura; aveia sem adubo }\end{array}$ \\
\hline 2 & $\begin{array}{l}\text { Pastagem contínua com } \\
\text { Brachiaria decumbens }\end{array}$ & Sem adubo \\
\hline 3 & $\begin{array}{l}\text { Soja/aveia/soja/pastagem } \\
\text { (B. decumbens) por } 2 \\
\text { anos }\end{array}$ & $\begin{array}{l}\text { Soja com } 350 \mathrm{~kg} \mathrm{ha}^{-1} \text { de adubo } \\
\text { formulado } 0-20-20 \text { a cada } \\
\text { semeadura; aveia sem } \\
\text { adubo; pastagem sem adubo }\end{array}$ \\
\hline 4 & $\begin{array}{l}\text { Pastagem } B . \text { decumbens } \\
\text { por } 2 \text { anos/soja/aveia/ } \\
\text { soja/pastagem } \\
(B . \text { decumbens })\end{array}$ & $\begin{array}{l}\text { Pastagem sem adubo; soja com } \\
350 \mathrm{~kg} \mathrm{ha}^{-1} \text { de adubo formulado } \\
0-20-20 \text { a cada semeadura; aveia } \\
\text { sem adubo }\end{array}$ \\
\hline 5 & $\begin{array}{l}\text { Soja/nabo/milho/aveia/ } \\
\text { pastagem }(B . \text { decumbens }) \\
\text { por } 2 \text { anos }\end{array}$ & $\begin{array}{l}\text { Soja com } 250-300 \mathrm{~kg} \mathrm{ha}^{-1} \mathrm{de} \\
\text { adubo formulado } 0-20-20 \text { a cada } \\
\text { semeadura; aveia e nabo sem } \\
\text { adubo, milho }+50 \mathrm{~kg} \mathrm{ha}^{-1} \mathrm{de} \mathrm{N} \text {; } \\
\text { pastagem sem adubo }\end{array}$ \\
\hline 6 & $\begin{array}{l}\text { Pastagem }(\text { B. decumbens }) \\
\text { por } 2 \text { anos/soja/aveia/ } \\
\text { soja/pastagem } \\
(B . \text { decumbens })\end{array}$ & $\begin{array}{l}\text { Pastagem sem adubo; soja com } \\
350 \mathrm{~kg} \mathrm{ha}^{-1} \text { de adubo formulado } \\
0-20-20 \text { a cada semeadura; aveia } \\
\text { sem adubo }\end{array}$ \\
\hline 7 & $\begin{array}{l}\text { Soja/nabo/milho/aveia/ } \\
\text { soja }\end{array}$ & $\begin{array}{l}\text { Soja com } 250-300 \mathrm{~kg} \mathrm{ha}^{-1} \text { de } \\
\text { adubo formulado } 0-20-20 \text { a cada } \\
\text { semeadura; aveia e nabo sem } \\
\text { adubo; milho }+50 \mathrm{~kg} \mathrm{ha}^{-1} \text { de N }\end{array}$ \\
\hline 8 & $\begin{array}{l}\text { Pastagem contínua com } \\
\text { B. brizantha }\end{array}$ & Sem adubo \\
\hline
\end{tabular}

(1)Número do tratamento. 
região. Os animais tiveram acesso livre às pastagens, sem controle de carga animal definido, apenas para rebaixamento da vegetação.

As parcelas foram agrupadas conforme a similaridade entre os sistemas de cultivo descritos a seguir: Lav, lavoura (sistemas 1 e 7); Past/Lav/Past, rotação pastagem/lavoura (sistemas 4 e 6); Lav/Past/ Lav, rotação lavoura/pastagem (sistemas 3 e 5) e Past, pastagem contínua (sistemas 2 e 8 ).

Decorridos dez anos da implantação das parcelas, em 2003 foram coletadas três amostras compostas em cada área, à profundidade de $0-20 \mathrm{~cm}$. O material foi secado ao ar e passado em peneira de $2 \mathrm{~mm}$ de malha, obtendose, assim, a terra fina seca ao ar (TFSA). Os teores de Ca, Mg, $\mathrm{Al}$ e K trocáveis, $\mathrm{P}$ extraído com Mehlich-1, pH em água, e carbono orgânico $\left(\mathrm{C}_{\text {org }}\right)$ foram determinados segundo Embrapa (1997). O nitrogênio foi obtido por destilação, em sistema semi-micro Kjeldahl, após digestão com $\mathrm{H}_{2} \mathrm{SO}_{4}$ e mistura catalisadora de sulfatos. A determinação foi feita por volumetria, após retenção do $\mathrm{NH}_{3}$ em ácido bórico (Tedesco et al., 1995).

Para o fracionamento da matéria orgânica do solo, foi utilizada a técnica de solubilidade diferencial (Kononova, 1966; Dabin, 1976), segundo modificação de Benites et al. (2003). Para se obterem o extrato alcalino, a fração ácido fúlvico (FAF) e a fração ácido húmico (FAH), utilizaram-se $20 \mathrm{~mL}$ de $\mathrm{NaOH} 0,1 \mathrm{~mol} \mathrm{~L}^{-1}$, por um período de 24 horas. A separação do extrato alcalino e do resíduo foi feita por centrifugação a $5.000 \mathrm{~g}$ ( $F R_{\text {média), por }} 30$ minutos. A seguir, foi feita mais uma lavagem, com a mesma solução anterior, juntando-se o extrato com o anteriormente obtido, o que resultou em volume final de aproximadamente $40 \mathrm{~mL}$. O resíduo foi reservado para determinação da humina (Hum).

$\mathrm{O}$ pH do extrato alcalino (EA) foi ajustado para 1, com $\mathrm{H}_{2} \mathrm{SO}_{4} 20 \%$, seguindo-se a decantação por 18 horas. A fração solúvel (FAF) foi separada da fração precipitada (FAH) por filtragem, e ambos os volumes foram aferidos a $50 \mathrm{~mL}$ com água destilada. A determinação quantitativa do carbono orgânico, nas FAF e FAH, foi feita usando-se alíquotas de $5 \mathrm{~mL}$ de extrato, $1 \mathrm{~mL}$ de dicromato de potássio $0,042 \mathrm{~mol} \mathrm{~L}^{-1} \mathrm{e}$ $5 \mathrm{~mL}$ de $\mathrm{H}_{2} \mathrm{SO}_{4}$ concentrado, em bloco digestor a $150^{\circ} \mathrm{C}$ (30 minutos), e titulação com sulfato ferroso amoniacal $0,0125 \mathrm{~mol} \mathrm{~L}^{-1}$.

No resíduo reservado, foi determinado o carbono orgânico na fração Hum, após secagem do material em estufa a $65^{\circ} \mathrm{C}$ (secagem completa), adicionando-se $5 \mathrm{~mL}$ de dicromato de potássio $0,167 \mathrm{~mol} \mathrm{~L}^{-1}, 10 \mathrm{~mL}$ de
$\mathrm{H}_{2} \mathrm{SO}_{4}$ concentrado, em bloco digestor a $150^{\circ} \mathrm{C}$ (30 minutos), e titulação com sulfato ferroso amoniacal $0,25 \mathrm{~mol} \mathrm{~L}^{-1}$.

Foram calculadas as relações entre os teores de carbono das frações ácido húmico e ácido fúlvico (FAH/ FAF), entre as frações solúveis no extrato alcalino $(\mathrm{EA}=\mathrm{FAF}+\mathrm{FAH})$ e a humina $(\mathrm{EA} / \mathrm{Hum})$, e o carbono orgânico não humificado $\left(\mathrm{CoNH}=\mathrm{C}_{\text {org }}\right.$ da amostra FAF - FAH - Hum).

Os resultados dos teores de carbono das frações húmicas e propriedades químicas, obtidos para os diferentes tratamentos estudados, foram submetidos ao teste de normalidade (Teste de Lilliefors) e à análise de variância com aplicação do teste $\mathrm{F}$, e os valores médios foram comparados entre si pelo teste de Scott-Knott a $5 \%$ de probabilidade.

\section{Resultados e Discussão}

Os resultados das análises químicas do solo, após dez anos de implantação do experimento, são apresentados na Tabela 2. Não foi verificada diferença significativa entre os tratamentos para os valores de $\mathrm{pH}$, que variaram de 6,2 a 6,6. Os valores observados são relativamente altos, quando comparados a outros latossolos da Região dos Cerrados (Freixo et al., 2002). Os maiores valores de $\mathrm{pH}$ observados podem ser decorrentes do manejo, em razão da calagem realizada antes da implantação das culturas, à qual as diferentes áreas vêm sendo submetidas.

Ao contrário do afirmado por Ciotta et al. (2002), sobre a perda do efeito residual da calagem e do efeito colateral da aplicação de fertilizantes solúveis (reação

Tabela 2. Propriedades químicas de um Latossolo Vermelho distroférrico, após implantação do experimento de diferentes sistemas de cultivo, à profundidade de $0-20 \mathrm{~cm}^{(1)}$.

\begin{tabular}{|c|c|c|c|c|c|c|c|}
\hline \multirow[t]{2}{*}{$\mathrm{T}^{(2)}$} & \multicolumn{7}{|c|}{ Atributo químico } \\
\hline & $\begin{array}{c}\mathrm{pH} \\
\left(\mathrm{H}_{2} \mathrm{O}\right)\end{array}$ & $\begin{array}{l}\mathrm{C}_{\text {org }} \\
--(\mathrm{g} \mathrm{kg}\end{array}$ & $\begin{array}{l}N_{\text {total }} \\
\left.g^{-1}\right)--\end{array}$ & $\mathrm{Ca}^{2-}$ & $\mathrm{Mg}^{2+}$ & $\begin{array}{c}\mathrm{K}^{+} \\
\left.\mathrm{g}^{-1}\right)^{---}\end{array}$ & $\begin{array}{c}\mathrm{P}(\text { Mehlich -1) } \\
\left(\mathrm{mg} \mathrm{kg}^{-1}\right)\end{array}$ \\
\hline 1 & $6,2 \mathrm{a}$ & $19,8 \mathrm{c}$ & $3,72 \mathrm{a}$ & $5,6 \mathrm{~b}$ & $3,3 a$ & $0,31 \mathrm{~d}$ & $5,0 \mathrm{a}$ \\
\hline 2 & $6,4 \mathrm{a}$ & $22,5 b$ & $3,61 \mathrm{a}$ & $6,2 \mathrm{a}$ & $3,4 \mathrm{a}$ & $0,28 \mathrm{~d}$ & $1,0 \mathrm{~b}$ \\
\hline 3 & $6,2 \mathrm{a}$ & $28,0 \mathrm{a}$ & $3,64 \mathrm{a}$ & $5,2 \mathrm{c}$ & $3,0 \mathrm{a}$ & $0,50 \mathrm{c}$ & $6,0 \mathrm{a}$ \\
\hline 4 & $6,2 \mathrm{a}$ & $26,0 \mathrm{a}$ & $3,21 \mathrm{~b}$ & $5,2 \mathrm{c}$ & $3,1 \mathrm{a}$ & $0,32 \mathrm{~d}$ & $1,0 \mathrm{~b}$ \\
\hline 5 & $6,3 \mathrm{a}$ & $21,1 \mathrm{c}$ & $3,51 \mathrm{a}$ & $5,2 \mathrm{c}$ & $3,5 \mathrm{a}$ & $1,10 \mathrm{a}$ & $6,0 \mathrm{a}$ \\
\hline 6 & $6,2 \mathrm{a}$ & $23,8 b$ & $3,33 b$ & $4,7 \mathrm{~d}$ & $3,5 \mathrm{a}$ & $0,38 \mathrm{c}$ & $2,0 \mathrm{~b}$ \\
\hline 7 & $6,6 \mathrm{a}$ & $16,6 \mathrm{~d}$ & $2,25 \mathrm{c}$ & $4,6 \mathrm{~d}$ & $3,1 \mathrm{a}$ & $0,78 b$ & $5,0 \mathrm{a}$ \\
\hline 8 & $6,2 \mathrm{a}$ & $23,3 \mathrm{~b}$ & $3,26 \mathrm{~b}$ & $4,9 \mathrm{~d}$ & $3,8 \mathrm{a}$ & $0,43 \mathrm{c}$ & $1,0 \mathrm{~b}$ \\
\hline
\end{tabular}

${ }^{(1)}$ Letras iguais, na mesma coluna, não diferem entre si pelo teste ScottKnott a 5\% de probabilidade. ${ }^{(2)}$ Número do tratamento. 
ácida) nas camadas superficiais, não foi constatada a ocorrência de acidificação neste experimento. Comportamento similar ao verificado neste estudo foi observado por Teixeira et al. (2003), ao estudar a variação dos valores de pH em Argissolo Vermelho-Amarelo, sob diferentes sistemas de preparo de solo.

Com relação ao $\mathrm{Ca}^{2+}$ trocável, observou-se diferença significativa entre os tratamentos, cujo menor valor verificado foi o do tratamento 7 (Lav), em que o teor de $\mathrm{Ca}^{2+}$ foi igual a 4,6 $\mathrm{cmol}_{\mathrm{C}} \mathrm{kg}^{-1}$, e o maior valor foi o do tratamento 2 (Past $-B$. decumbens), com teor igual a $6,2 \mathrm{cmol}_{\mathrm{C}} \mathrm{kg}^{-1}$; para o $\mathrm{Mg}^{2+}$ não foram verificadas diferenças significativas entre os tratamentos. Para o $\mathrm{K}^{+}$trocável, foram observadas diferenças significativas entre os tratamentos, em que o tratamento 2 (Past - B. decumbens) apresentou o menor valor, $0,28 \mathrm{cmol}_{\mathrm{c}} \mathrm{kg}^{-1}$, e o 5 (Lav/Past/Lav) o maior valor, $1,10 \mathrm{cmol}_{\mathrm{C}} \mathrm{kg}^{-1}$ (Tabela 2).

Quanto aos teores de P, observou-se uma similaridade dentro dos grupos de cobertura, com os menores valores para os tratamentos 2 e 8 (Past) e os maiores valores para os tratamentos 3 e 5 (Lav/Past/Lav) (Tabela 2). Os baixos valores de P podem ser decorrentes da adsorção de P, promovida pelos óxidos de ferro presentes no perfil, ou pela extração e remoção pelas culturas.

Observando-se a rotação de culturas e o manejo da adubação nos diferentes tratamentos (Tabela 1 ), verifica-se que, durante o período de dez anos, o tratamento 5 foi o que recebeu menor número de adubações com K e P (três vezes), em relação aos tratamentos 1 e 7 (dez e sete vezes), enquanto para os tratamentos 3 , 4 e 6, o número de vezes variou de quatro a seis. Essa diferença nos teores desses nutrientes, no tratamento 5 , pode ser atribuída à rotação de culturas utilizada (Lav/ Past/Lav) ou à presença do nabo, durante a rotação de culturas, ou à utilização de $B$. brizantha, durante o período de pastagem.

Os valores de $C_{\text {org }}$ variaram de 16,6 $\mathrm{g} \mathrm{kg}^{-1}$ a $28 \mathrm{~g} \mathrm{~kg}^{-1}$, sendo o menor valor observado no tratamento 7 , e o maior valor no tratamento 3 . Verificou-se que os tratamentos 3 e 4 não diferiram significativamente entre si, o que indica que as rotações Lav/Past/Lav e Past/Lav/ Past contribuíram igualmente para o aumento do conteúdo de $\mathrm{C}_{\text {org }}$ das áreas (Tabela 2). Tormena et al. (2004), ao estudar a taxa de estratificação de carbono orgânico num Latossolo Vermelho, após dez anos sob plantio direto, verificaram maiores valores de carbono orgânico na camada superficial das áreas estudadas.
O tratamento 3 diferiu significativamente do tratamento 5, embora fossem ambos do mesmo grupo (Lav/Past/ Lav). Esta diferença pode ser decorrente da rotação de espécies, dentro de cada tratamento. No tratamento 3 , houve uma seqüência de leguminosa e gramínea, diferindo do tratamento 5 , que consistiu do plantio de uma leguminosa e de uma brássica (nabo forrageiro), seguido por três ciclos de cultivos de gramíneas e, posteriormente, do plantio de uma leguminosa.

Os tratamentos 1 e 7, ambos lavoura (Lav), apresentaram diferenças significativas entre si. No tratamento 7 , além de soja e aveia, foi utilizado nabo forrageiro e milho, estabelecendo-se desta forma um cultivo com leguminosa, um com brássica e dois com gramínea. O menor valor de $C_{\text {org }}\left(16,6 \mathrm{~g} \mathrm{~kg}^{-1}\right)$ no tratamento 7 parece indicar uma forma menos adequada de manejo, quando comparada aos demais (Tabela 2).

Os sistemas de cultura/rotação, utilizados nos tratamentos 4 e 6 , foram idênticos; tais tratamentos diferenciam-se dos demais apenas pelo tipo de pastagem implantada, $B$. decumbens no tratamento 4 e $B$. brizantha no tratamento 6 , ambos seguidos de soja e aveia. Os tratamentos foram significativamente diferentes entre si, tendo o tratamento 4 apresentado maiores valores, quando comparado ao 6. É provável que a pastagem com $B$. decumbes tenha se adaptado melhor após soja e aveia, do que a pastagem com B. brizantha, e que tenha contribuído para o aumento do teor de carbono no solo. Todavia, quando os tratamentos 2 e 8 foram comparados somente com pastagens permanentes, B. decumbens e B. brizantha, não apresentaram diferenças entre si.

D’Andréa et al. (2004), em estudos sobre estoque de carbono, nitrogênio e formas de nitrogênio mineral, em um solo submetido a diferentes sistemas de manejo, no Município de Morrinhos, GO, verificaram que a pastagem, principalmente $B$. decumbens, é um sistema promissor em promover aumentos nos estoques de $C_{\text {org }}$ do solo em profundidade. Este comportamento também pode ser verificado no sistema de plantio direto, desde que se adote um esquema de rotação de culturas.

Tais resultados mostram-se semelhantes aos verificados por Souza \& Alves (2003), que em trabalhos com solo de cerrado, no Mato Grosso do Sul, encontraram valores de $\mathrm{C}_{\text {org }}$ de $21,6 \mathrm{~g} \mathrm{~kg}^{-1} \mathrm{em}$ áreas de plantio direto (oito anos de implantação) e 21,2 $\mathrm{g} \mathrm{kg}^{-1}$ em sistemas de cultivo mínimo (oito anos de implantação), diferindo do encontrado para a área de pastagem de $B$. decumbens, com valores de $\mathrm{C}_{\text {org }}$ na ordem de $12,7 \mathrm{~g} \mathrm{~kg}^{-1}$ (20 anos 
de implantação). Nesse mesmo trabalho, os autores observaram que os sistemas de plantio direto e cultivo mínimo propiciaram aumentos significativos da matéria orgânica do solo, cálcio, magnésio, fósforo, potássio, elevação do pH, maior CTC e soma de bases e diminuição dos teores de alumínio, em relação ao sistema de plantio convencional.

No presente estudo, os valores de nitrogênio variaram de $2,25 \mathrm{~g} \mathrm{~kg}^{-1}$ a $3,72 \mathrm{~g} \mathrm{~kg}^{-1}$, cujo menor valor observado foi no tratamento 7 e o maior valor, no tratamento 1. O comportamento verificado para o nitrogênio mostra que o tratamento 1 , seqüência de cultivo soja/ aveia, propiciou maior contribuição da fixação biológica de nitrogênio (FBN) da cultura da soja, em relação aos demais tratamentos com rotações variadas e pastagem permanente (Tabela 2).

Os tratamentos 2 e 8 (Past) apresentaram diferenças estatísticas significativas entre si, com destaque para o tratamento 2 , com cobertura de $B$. decumbens, que apresentou maior valor de $\mathrm{N}$ total acompanhando os valores de $\mathrm{C}_{\text {org. }}$.

Ao se compararem os valores de $\mathrm{N}$ total do grupo Lav/Past/Lav (tratamentos 3 e 5) com os do grupo Past/ Lav/Past (tratamentos 4 e 6), verificam-se diferenças significativas, com os maiores valores observados para a primeira seqüência de rotação. O maior valor de $\mathrm{N}$ total, principalmente, no tratamento 3 , pode ser decorrente do maior número de cultivos com soja, na sucessão de culturas (seis vezes), o que contribui com o efeito residual da fixação biológica de nitrogênio.

Quanto às frações da matéria orgânica, verifica-se o predomínio da Hum, seguida pelas FAH e FAF (Tabela 3). Os elevados valores da Hum podem estar relacionados ao tamanho das moléculas e ao maior grau de estabilidade desta fração. As FAF e FAH, por apresentar menor estabilidade, podem ser translocadas para camadas mais profundas, ser polimerizadas ou mineralizadas, e diminuir, assim, seu teor residual no solo.

Rosales et al. (1999), ao estudar o estoque total de carbono orgânico e seus compartimentos, em Argissolo sob floresta e milho cultivado com adubação mineral e orgânica em Viçosa, MG, verificaram maiores valores da Hum em todos os sistemas de produção, relacionados ao tamanho das moléculas e ao longo tempo de implantação do experimento.

Para a FAF, não foi observada diferença significativa entre os tratamentos, com valores de 2,4 a $3,3 \mathrm{~g} \mathrm{~kg}^{-1}$. Em relação à FAH, foi constatada diferença entre os tratamentos, com o menor valor $\left(1,3 \mathrm{~g} \mathrm{~kg}^{-1}\right)$ verificado no tratamento 7, e o maior valor $\left(4,1 \mathrm{~g} \mathrm{~kg}^{-1}\right)$ no tratamento 1. Quanto à Hum, o menor valor ocorreu no tratamento 7 (Lav) e o maior valor no tratamento 2 (Past).

Os valores para a relação FAH/FAF variaram entre 1,37 (tratamento 1) e 0,58 (tratamento 7), sendo ambos os tratamentos sob lavoura. Os baixos valores da relação FAH/FAF indicam que os sistemas de manejo adotados, ou as seqüências de culturas implantadas, podem estar favorecendo a degradação das frações mais estáveis ou desfavorecendo sua formação.

Para a relação EA/Hum, os valores encontrados foram todos menores que 1 , destacando-se o tratamento 7 com o menor deles $(0,50)$. Estes resultados demonstram que a Hum (fração mais estável) predomina sobre as demais frações (FAF e FAH). Leite et al. (2003), ao estudar o estoque total de carbono orgânico e seus compartimentos, em Argissolo sob floresta e milho cultivado com adubação mineral e orgânica, em Viçosa, MG, verificaram maiores valores da relação FAH/FAF em solo sob floresta do que em solo sob sistemas de produção. Os autores atribuíram os maiores valores desta relação, na área de floresta, ao menor grau de perturbação da área, o que promove uma maior polimerização de compostos húmicos e favorece a proporção FAH, em relação à FAF.

Analisando-se os gráficos de distribuição das frações, pode-se observar que todos os tratamentos apresentaram a maior parte do $\mathrm{C}_{\text {org }}$ na forma humificada (Figura 1). No tratamento 1, observa-se uma distribuição diferenciada em relação às demais, destacando-se com mais de $50 \%$ do $\mathrm{C}_{\text {org }}$ representado pela fração Hum, e apenas $11 \%$ do $\mathrm{C}_{\text {org }}$ na forma de CoNH. A seqüência

Tabela 3. Frações da matéria orgânica $\left(\mathrm{g} \mathrm{kg}^{-1}\right)$, relação FAH/ FAF e EA/Hum, de um Latossolo Vermelho distroférrico, sob diferentes coberturas e manejos ${ }^{(1)}$.

\begin{tabular}{ccccccc}
\hline $\mathrm{T}^{(2)}$ & FAF & FAH & Hum & $\begin{array}{c}\text { Soma } \\
\text { frações }\end{array}$ & FAH/FAF EA/Hum \\
\hline 1 & $3,0 \mathrm{a}$ & $4,1 \mathrm{a}$ & $10,6 \mathrm{a}$ & 17,7 & 1,37 & 0,67 \\
2 & $2,7 \mathrm{a}$ & $3,5 \mathrm{a}$ & $10,9 \mathrm{a}$ & 17,1 & 1,30 & 0,57 \\
3 & $3,3 \mathrm{a}$ & $3,4 \mathrm{a}$ & $10,2 \mathrm{a}$ & 16,9 & 1,03 & 0,66 \\
4 & $2,7 \mathrm{a}$ & $3,0 \mathrm{a}$ & $9,9 \mathrm{a}$ & 15,6 & 1,11 & 0,58 \\
5 & $3,2 \mathrm{a}$ & $3,3 \mathrm{a}$ & $10,2 \mathrm{a}$ & 16,7 & 1,03 & 0,64 \\
6 & $2,9 \mathrm{a}$ & $2,6 \mathrm{a}$ & $8,8 \mathrm{~b}$ & 14,3 & 0,90 & 0,63 \\
7 & $2,4 \mathrm{a}$ & $1,3 \mathrm{~b}$ & $7,4 \mathrm{c}$ & 11,1 & 0,58 & 0,50 \\
8 & $2,7 \mathrm{a}$ & $2,8 \mathrm{a}$ & $9,7 \mathrm{a}$ & 15,2 & 1,04 & 0,57 \\
\hline
\end{tabular}

${ }^{(1)}$ Letras iguais, na mesma coluna, não diferem entre si pelo teste ScottKnott a 5\%; FAF: fração ácido fúlvico; FAH: fração ácido húmico; Hum: humina; EA: FAF + FAH. ${ }^{(2)}$ Número do tratamento. 


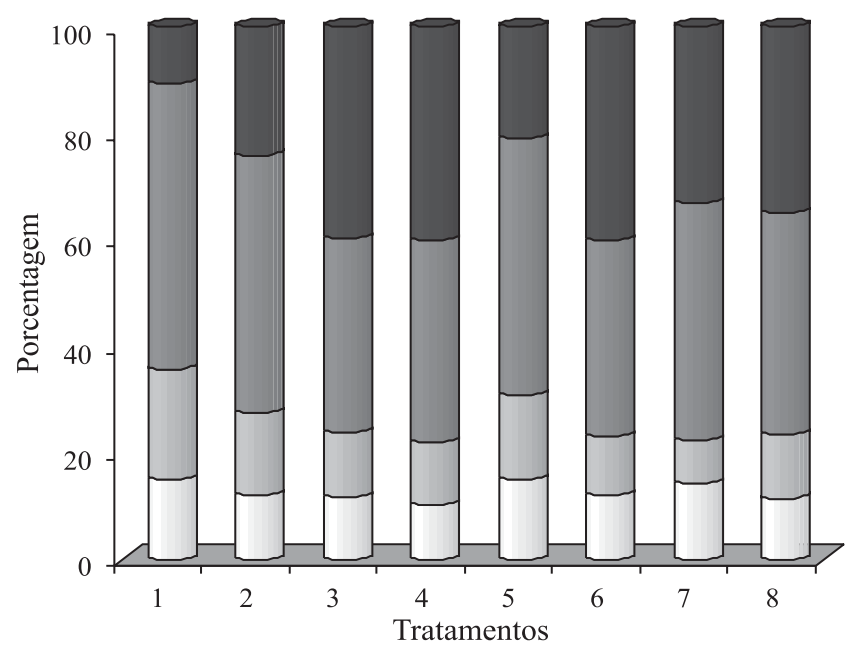

Figura 1. Distribuição, em porcentagem, das frações húmicas do solo (fração ácido fúlvico, $\square$; fração ácido húmico, $\square$; e humina, $\square$ ) e carbono orgânico não humificado ( $\square$ ), nos tratamentos estudados.

leguminosa/gramínea se destaca entre as demais rotações, neste ponto de observação e, assim, mesmo que não possibilite um aumento significativo do teor de $\mathrm{C}_{\text {org }}$, o uso desta rotação, em longo prazo, poderá permitir a manutenção da qualidade desses solos, indicada pela alta porcentagem de $\mathrm{CoH}$.

\section{Conclusões}

1. Após dez anos de experimento, os sistemas de cultivo apresentaram comportamentos diferenciados entre os teores de nutrientes e $\mathrm{pH}$.

2. O tratamento 7 (Lav) apresenta o menor teor de carbono orgânico, enquanto os tratamentos 3 e 4 (Lav/ Past/Lav e Past/Lav/Past, respectivamente), os maiores teores; a humina foi a fração húmica de maior expressão na maioria dos tratamentos.

3. A rotação soja/aveia, em plantio direto, em solo de Cerrado contribui para a humificação e manutenção da matéria orgânica do solo.

\section{Referências}

BENITES, V.M.; MADARI, B.; MACHADO, P.L.O. de A. Extração e fracionamento quantitativo de substâncias húmicas do solo: um procedimento simplificado de baixo custo. Rio de Janeiro: Embrapa Solos, 2003. 7p. (Embrapa Solos. Comunicado técnico, 16).

CERRI, C.C.; FELLER, C.; CHAUVEL, A. Evolução das principais propriedades de um Latossolo Vermelho Escuro após desmatamento e cultivo por doze e cinqüenta anos com cana-de-açúcar. Cahiers ORSTOM, Série Pédologie, v.26, p.37-50, 1991.
CIOTTA, M.N.; BAYER, C.; ERNANI, P.R.; FONTOURA, S.M.V.; ALBUQUERQUE, J.A.; WOBETO, C. Acidificação de um latossolo sob plantio direto. Revista Brasileira de Ciência do Solo, v.26, p.1055-1064, 2002.

DABIN, B. Méthode d'extraction et de fractionnement des matières humiques du sol: application à quelques études pédologiques et agronomiques dans les sols tropicaux. Cahiers ORSTOM, Série Pédologie, v.14, p.287-297, 1976.

D’ANDRÉA, A.F.; SILVA, M.L.N.; CURI, N.; GUILHERME, L.R.G. Estoque de carbono e nitrogênio e formas de nitrogênio mineral em um solo submetido a diferentes sistemas de manejo. Pesquisa Agropecuária Brasileira, v.39, p.179-186, 2004.

EMBRAPA. Centro Nacional de Pesquisa de Solos (Rio de Janeiro, RJ). Manual de métodos de análise de solos. 2.ed. Rio de Janeiro, 1997. 212p. (Embrapa-CNPS. Documentos, 1).

FONTANA, A.; PEREIRA, M.G.; NASCIMENTO, G.B.; ANJOS, L.H.C. dos; EBELING, A.G. Frações da matéria orgânica e fertilidade de solos de Tabuleiro sob diferentes coberturas vegetais no norte fluminense - RJ. In: JORNADA DE INICIAÇÃO CIENTÍFICA DA UFRRJ, 11., 2001, Seropédica. Anais. Seropédica: UFRRJ, 2001. p.3-6.

FREIXO, A.A.; MACHADO, P.L.O.A. de; GUIMARÃES, C.M.; SILVA, C.A.; FADIGAS, F.S. Estoques de carbono e nitrogênio e distribuição de frações orgânicas de latossolo do Cerrado sob diferentes sistemas de cultivo. Revista Brasileira de Ciência do Solo, v.26, p.425-434, 2002.

HERMANI, L.C.; KURIHARA, C.H.; SILVA, W.M. Sistemas de manejo de solo e perdas de nutrientes e matéria orgânica por erosão. Revista Brasileira de Ciência do Solo, v.23, p.145-154, 1999.

KONONOVA, M.M. Soil organic matter. $2^{\text {nd }}$ ed. New York: Pergamon Press, 1966. 555p.

LEITE, L.F.C.; MENDONÇA, E.S.; NEVES, J.C.L.; MACHADO, P.L.O. de; GALVÃO, J.C.C. Estoques totais de carbono orgânico e seus compartimentos em argissolo sob floresta e sob milho cultivado com adubação mineral e orgânica. Revista Brasileira de Ciência do Solo, v.27, p.821-832, 2003.

MENDONZA, H.N.S.; LIMA, E.; ANJOS, L.H.C.; SILVA, L.A.; CEDDIA, M.B.; ANTUNES, M.V.M. Propriedades químicas e biológicas de solo de Tabuleiro cultivado com cana-de-açúcar com e sem queima da palhada. Revista Brasileira de Ciência do Solo, v.24, p.201-207, 2000.

PAIVA, P.L.R.; FURTINI NETO, A.E.; VALE, F.R.; FAQUIN, V. Efeito do manejo do solo sobre os teores de matéria orgânica, nitrogênio mineral, fósforo e bases trocáveis. Ciência e Agrotecnologia, v.21, p.35-43, 1997.

ROSALES, M.A.; OLIVEIRA, O.S.; MOURA, M.A.; LOURES, E.G. Influência das adubações orgânica e mineral contínuas sobre as características das frações das substâncias húmicas do solo. Revista Ceres, v.46, p.67-81, 1999.

SELLES, F.; KOCHANN, R.A.; DENARDIN, J.E.; ZENTNER, R.P.; FAGANELLO, A. Distribution of phosphorus fractions in a Brazilian oxisol under different tillage systems. Soil and Tillage Research, v.44, p.23-34, 1997. 
SILVA, C.F. Indicadores da qualidade do solo em áreas de agricultura tradicional no entorno do Parque Estadual da Serra do Mar em Ubatuba (SP). 2005. 80p. Dissertação (Mestrado) Universidade Federal Rural do Rio de Janeiro, Seropédica.

SILVA, L.S.; CAMARGO, F.A.O.; CERRETA, C.A. Composição da fase sólida orgânica do solo. In: MEURER, E.J. (Ed.). Fundamentos de química do solo. Porto Alegre: Gênesis, 2000. 174p.

SILVEIRA, P.M.; STONE, L.F. Teores de nutrientes e matéria orgânica afetados pela rotação de culturas e sistema de preparo do solo. Revista Brasileira de Ciência do Solo, v.25, p.387-394, 2001.

SOUZA, Z.M.; ALVES, M.C. Propriedades químicas de um Latossolo Vermelho distroférrico de cerrado sob diferentes usos e manejos. Revista Brasileira de Ciência do Solo, v.27, p.133-139, 2003.

TEDESCO, M.G.; GIANELO, C.; BISSANI, C.A.; BOHNEN, H.; VOLKWEISS, S.J. Análise de solo, plantas e outros materiais. Porto Alegre: Departamento de solos da UFRGS, 1995. 174p.

TEIXEIRA, I.R.; SOUZA, C.M.; BORÉM, A.; SILVA, G.F. Variação dos valores de pH e dos teores de carbono orgânico, cobre, manganês, zinco e ferro em profundidade em Argissolo Vermelho-Amarelo, sob diferentes sistemas de preparo do solo. Bragantia, v.62, p.119-126, 2003.

TORMENA, C.A.; FRIEDRICH, R.; PINTRO, J.C.; COSTA, A.C.S.; FIDALSKI, J. Propriedades físicas e taxa de estratificação de carbono orgânico num Latossolo Vermelho após dez anos sob dois sistemas de manejo. Revista Brasileira de Ciência do Solo, v.28, p.1023-1031, 2004.

TORRES, J.L.R.; PEREIRA, M.G.; ANDRIOLI, A.; POLIDORO, J.C.; FABIAN, A.J. Decomposição e liberação de nitrogênio de resíduos culturais de plantas de cobertura em um solo de cerrado. Revista Brasileira de Ciência do Solo, v.29, p.609-618, 2005.

VAUGHAN, D.; ORD, B.G. Soil organic matter: a perspective on its nature, extraction, turnover and role in soil fertility. In: VAUGHAN, D.; MALCOLM, R.E. (Ed.). Soil organic matter and biological activity. Boston: Martinus \& Junk, 1985. p.34. (Developments in plant and soil sciences, 16).

VOLKOFF, B.; CERRI, C.C. L'humus des sols du Brésil: nature et relations avec l'environnement. Cahiers ORSTOM, Série Pédologie, v.24, p.83-95, 1988.

Recebido em 3 de março de 2005 e aprovado em 11 de outubro de 2005 